\title{
Is Workaholism Good or Bad for Employee Well-being? The Distinctiveness of Workaholism and Work Engagement among Japanese Employees
}

\author{
Akihito SHIMAZU ${ }^{1 *}$ and Wilmar B. SCHAUFELI ${ }^{2}$ \\ ${ }^{1}$ Department of Mental Health, The University of Tokyo Graduate School of Medicine, 7-3-1 Hongo, Bunkyo- \\ ku, Tokyo 113-0033, Japan \\ ${ }^{2}$ Department of Social and Organizational Psychology, Utrecht University, P.O. Box 80.140, 3508 TC Utrecht, \\ The Netherlands
}

Received May 27, 2009 and accepted July 9, 2009

\begin{abstract}
The aim of the present study is to demonstrate the empirical distinctiveness of workaholism and work engagement by examining their relationships with well-being in a sample of $\mathbf{7 7 6}$ Japanese employees. We expected that workaholism is associated with unwell-being (i.e., high psychological distress and physical complaints, low job and family satisfaction, and low job performance), whereas work engagement is associated with well-being. Well-validated questionnaires were used to measure workaholism (DUWAS), work engagement (UWES), and well-being (BJSQ, HPQ). Structural Equation Modeling showed that, as expected, workaholism was positively associated with ill-health (i.e., psychological distress and physical complaints) and negatively associated with life satisfaction (i.e., job and family satisfaction) and job performance. In contrast, work engagement was negatively associated with ill-health and positively associated with life satisfaction and job performance. These findings suggest that workaholism and work engagement are two different kinds of concepts, which are negatively and positively related to various indicators of well-being, respectively.
\end{abstract}

Key words: Family satisfaction, Job performance, Job satisfaction, Structural equation modeling, Physical complaints, Psychological distress, Workaholism, Work engagement

\section{Introduction}

In recent years, working conditions have rapidly been changing. For instance, clear role expectations at work do not exist anymore ${ }^{1)}$ and the boundaries between work and personal life are becoming more blurred ${ }^{2}$. In addition, with the advancement of technology (e.g., internet and telecommunication), more and more employees are able to work outside the traditional office and beyond traditional work hours ${ }^{3}$. These changes of work conditions call for a better understanding of how employees feel about their work as well as where they work (i.e., job

*To whom correspondence should be addressed.

E-mail: ashimazu@m.u-tokyo.ac.jp characteristics). This study focuses on workaholism and work engagement and differentiates between both by investigating the associations of both concepts with employees' well-being (i.e., psychological and physical health, job and family satisfaction, and job performance). The empirical distinctiveness between workaholism and work engagement is particularly important because some conceptual confusion exists about the nature of these two overlapping concepts ${ }^{4)}$.

\section{Workaholism}

For the lay public workaholism seems synonymous with working extremely hard. However, conceiving workaholism exclusively in terms of the number of working hours is misleading because it neglects its addictive 
nature. A typical work addict is motivated by a strong internal drive that cannot be resisted rather than being motivated by external or contextual factors, such as financial problems, poor marriage, organizational culture, supervisory pressure, or a strong desire for career advancement. This follows from the overview of earlier theory and research as performed by Scott et al. ${ }^{5)}$, who found three common characteristics of workaholism that feature across various definitions. First, workaholics spend a great deal of time on work activities when given the discretion to do so - they are excessively hard workers. Second, workaholics are reluctant to disengage from work and they persistently and frequently think about work when they are not at work. This suggests that workaholics are obsessed with their work - they are compulsive workers. The third common feature - workaholics work beyond what is reasonably expected from them to meet organizational or economic requirementsis, in fact, a specification of the first and the second features because it deals with a particular manifestation of working hard and compulsively.

Therefore, based on a conceptual analysis, Schaufel et $a l .{ }^{4)}$ defined workaholism as the tendency to work excessively hard (the behavioral dimension) and being obsessed with work (the cognitive dimension), which manifests itself in working compulsively. This definition agrees with the most recent analysis of scholarly definitions that concludes that hard work at the expense of other important life roles and a strong internal drive to work are two key aspects of workaholism ${ }^{3)}$.

\section{Work engagement}

The concept of work engagement emerged from burnout research, namely as an attempt to cover the entire spectrum running from employee unwell-being (burnout) to employee well-being6). In order to prosper and survive in today's continuously changing environment, rather than merely "healthy" employees, organizations need engaged employees. Work engagement refers to a positive, fulfilling, work-related state of mind that is characterized by vigor, dedication, and absorption ${ }^{7}$. Vigor is characterized by high levels of energy, the willingness to invest effort in one's work, and persistence also in the face of difficulties. Dedication refers to being strongly involved in one's work, and experiencing a sense of significance, enthusiasm, inspiration, pride, and challenge. Finally, absorption is characterized by being fully concentrated and engrossed in one's work, whereby time passes quickly and one has difficulties with detaching oneself from work.

Thus engaged employees work hard (vigor), are involved (dedicated) and feel engrossed (absorbed) in their work. In this sense they seem similar to worka- holics. However, in contrast to workaholics, engaged workers lack the typical compulsive drive. For them work is fun, not an addiction, they work hard because they like their job (intrinsic motivation) and not because they feel driven by an obsessive inner drive they cannot resist, as was concluded from a qualitative interview $s\left(u d y{ }^{8}\right.$. So, despite the fact that workaholics and engaged employees may work similarly hard, their motivation to do so differs fundamentally. It is interesting to note that workaholism shows a positive relationship with excess working time ${ }^{4,9)}$, whereas this relationship is absent for work engagement ${ }^{4}$.

To sum up, both workaholism and work engagement are individual attitudes (i.e., behaviors and cognitions) towards work that share their behavioral aspect (work excessively hard). However, the underlying motivation for this behavior (i.e., the cognitive aspect) differs: workaholics are propelled by an obsessive inner drive they cannot resist, whereas engaged employees are intrinsically motivated.

\section{Correlates of workaholism}

By definition, workaholics spend an excess amount of time on their work. This suggests that they have insufficient opportunity to recover from their excessive efforts $^{10)}$, leaving them emotionally or cognitively exhausted over time ${ }^{11)}$. In addition, they persistently and frequently think about work when they are not at work ${ }^{11)}$, which may result in sympathic arousal and emotional distress. Consequently, workaholics report relatively high levels of psychological distress and physical complaints $^{4,11-17)}$.

Another type of outcome concerns satisfaction such as job and family satisfaction. Because workaholics work hard not because they like their job but because of an obsessive inner drive they tend to report low levels of job satisfaction ${ }^{18,19)}$. In addition, their tendency to invest much time and effort in their work at the expense of their important life roles ${ }^{3)}$ is likely to lead to impaired family functioning. In line with this notion, previous studies revealed that workaholics reported low family satisfaction $^{19,20)}$, poor relationship quality with partners ${ }^{21,22)}$, and high work-family conflict ${ }^{11,21)}$.

Besides ill-health and life satisfaction, another relevant outcome associated with workaholism is job performance. Schaufeli et al. ${ }^{23)}$ argued that workaholics work hard rather than smart; they create difficulties for themselves and their co-workers, suffer from perfectionism, are rigid and inflexible, and do not delegate. Unfortunately, virtually no empirical research has been carried out on the relationship between workaholism and job performance with one notable exception ${ }^{23)}$. Although Schaufeli et al. $(2006)^{23)}$ showed that both components of workaholism 
(i.e., work excessively hard and working compulsively) were weakly positively related to self-reported extra-role performance, we expect that workaholics are not necessarily good and are perhaps even poor performers, given the long list of negative attitudes and behaviors that might interfere with job performance ${ }^{5}$.

\section{Correlates of work engagement}

Because work engagement was introduced as an antipode of burnout, it is expected that work engagement is primarily related to (lack of) health problems. Indeed, previous studies revealed that work engagement was negatively related to psychological distress and physical complaints $^{4,}$, 19, 23-25).

Regarding life satisfaction, engaged workers work hard because they like their job (intrinsic motivation) not because they are driven by an obsessive inner drive ${ }^{8}$. Therefore, previous studies showed that engaged workers report high job satisfaction ${ }^{4,25)}$. In addition, structured qualitative interviews showed that engaged workers are active agents and also seem to be engaged in other activities outside their work ${ }^{8}$. This suggests that their family satisfaction is high.

Finally, there are at least four reasons why engaged workers perform better than non-engaged workers ${ }^{26}$. Engaged employees: (1) often experience positive emotions, including happiness, joy, and enthusiasm; (2) experience better health; (3) create their own job resources and personal resources; and (4) transfer their engagement to others. In line with these notions, Schaufeli et al. $\left.(2006)^{23}\right)$ showed that engaged workers reported higher in-role and extra-role performance and innovativeness. In addition, a study among Spanish hotels and restaurants showed that employees' levels of work engagement had a positive impact on the service climate of these hotels and restaurants, which, in its turn, predicted employees' extra-role behavior as well as customer satisfaction ${ }^{27}$. Finally, the level of engagement of the staff of a particular shift of a fast food restaurant was positively related to the financial return that was obtained for that shift ${ }^{28)}$. Hence, it seems that work engagement is positively related to job performance.

To sum up, according to the Job Demands-Resource model ${ }^{29)}$ work engagement plays a key-role in the motivational process, which links job resources via work engagement with organizational outcomes (e.g., turnover intention), whereas burnout plays a key-role in the health impairment process, which links job demands via burnout with health problems. Workaholism can be seen as an individual risk factor to develop burnout.

\section{This study}

Previous studies which examined the distinctiveness between workaholism and work engagement suggest that they share the behavioral component (work excessively hard), but that the underlying motivation differs fundamentally $4,9,23)$. In addition, the studies mentioned above suggest that workaholism is related to unwell-being, whereas work engagement to well-being. However, there has been only one empirical study that examined the distinctiveness of workaholism and work engagement in terms of their relationships with well-being ${ }^{23)}$. This study used a very broad and heterogeneous internet sample. Hence, an investigation among a homogeneous sample of employees still stands out.

Therefore, the aim of the present study is to demonstrate the empirical distinctiveness of workaholism and work engagement by examining their relationships with well-being in a sample of Japanese employees from a specific company. In line with the discussion above, we expected that workaholism and work engagement are weakly and positively related to each other (Hypothesis 1). In addition, we formulated the following two hypotheses regarding the associations of workaholism and work engagement with employees' well-being.

Hypothesis 2: Workaholism is positively related to illhealth (i.e., psychological distress and physical complaints), and negatively related to life satisfaction (i.e., job satisfaction and family satisfaction) and job performance.

Hypothesis 3: Work engagement is negatively related to ill-health, and positively related to life satisfaction and job performance.

\section{Methods}

\section{Participants}

All employees, who worked at direct and indirect divisions of a construction machinery company in western Japan, were invited by the industrial health staff of the company to participate in the study. Those in the direct division were engaged in the production assembly line, whereas those in the indirect division were engaged in supportive tasks (e.g., supplementation of materials and clerical tasks). Before participating, all employees were informed about the objectives of the study by a pamphlet as well as by their supervisors. The study was approved by the ethics review board of Hiroshima University before starting the study.

Questionnaires were distributed to all employees $(\mathrm{N}=969)$ and 922 employees returned the questionnaires (95.1\% response rate). Missing data for one or more key study variables reduced this number to 776 . Of these respondents, $728(93.8 \%)$ were males and 48 females (6.2\%); 578 (74.5\%) were members of the direct division and $198(25.5 \%)$ were members of the indirect division. The mean age of the sample was $38.1 \mathrm{yr}(\mathrm{SD}=12.8)$. 


\section{Measures}

The questionnaire included the following six aspects; workaholism, work engagement, ill-health, life satisfaction, job performance and possible confounders. All measures were in Japanese and well-validated.

Workaholism: Workaholism was measured with the Dutch Workaholism Scale (DUWAS) developed by Schaufeli and his colleagues ${ }^{9}$. The scale consists of two subscales; Working Excessively (e.g., I stay busy and keep many irons in the fire) and Working Compulsively (e.g., I feel guilty when I take time off work). Each subscale consists of 5 items which were rated on a 4-point Likert scale ( $1=$ totally disagree, $4=$ totally agree).

Work engagement: Work engagement was assessed with the short form of the Utrecht Work Engagement Scale $(\mathrm{UWES})^{7}$, that has recently been validated in Japan as well ${ }^{25}$. The UWES includes three subscales that reflect the underlying dimensions of engagement: Vigor (3 items; e.g., At my job, I feel strong and vigorous), Dedication (3 items; e.g., I am enthusiastic about my job), and Absorption (3 items; e.g., I am immersed in my work). All items are scored on a seven-point Likert scale ranging from 0 ('never') to 6 ('always').

Ill-health: Psychological distress was assessed using the corresponding subscales of the Brief Job Stress Questionnaire (BJSQ) ${ }^{30)}$. Psychological distress was measured by means of 15 items, mainly reflecting fatigue, anxiety, and depression. For instance, "I am tired completely", "I feel ill at ease", and "I feel depressed". Each item was scored on a four-point Likert scale ranging from " $1=$ strongly disagree" to " $4=$ strongly agree".

Physical complaints was also assessed using the corresponding subscales of $\mathrm{BJSQ}^{30)}$ consisting of 11 items, like "I have a pain in the back". Each item was scored on a four-point Likert scale ranging from "1=strongly disagree" to " $4=$ strongly agree".

Life satisfaction: Job satisfaction was assessed using a single item, that is, whether or not the participant was satisfied with his/her job ${ }^{30)}$. It has been argued that a global index of overall job satisfaction (single item measure) is an inclusive and valid measure of general job satisfac$\operatorname{tion}^{31-33)}$. The job satisfaction item was scored on a fourpoint Likert scale ranging from " $1=$ satisfied" to " $4=$ dissatisfied". It was reversely scored so that a high score indicates a high level of job satisfaction.

Family satisfaction was also assessed using a single item, that is, whether or not the participant was satisfied with his/her family ${ }^{30}$. This item was scored on a fourpoint Likert scale ranging from " $1=$ satisfied" to " $4=$ dissatisfied". It was also reversely scored so that a high score indicated a high level of family satisfaction.

Job performance: Job performance was assessed using a single item from the World Health Organization Health and Work Performance Questionnaire (HPQ $)^{34)}$. Respondents were asked to rate their overall work performance during the past four wk on a 0-10 self-anchoring scale, in which 0 is defined as the "worst possible work performance a person could have on this job" and 10 is defined as "top work performance" on the job. We used the single-item self-report global scale because; 1 ) it has been argued that a global index of overall job performance (single item measure) is an inclusive and valid measure of job performance ${ }^{34)}$; 2) data on the objective performance of employees is difficult to obtain; and 3) alternative self-report measures of job performance focus on single occupations and include questions tailored to the unique demands of those occupations.

Possible confounders: As possible confounders, age, gender, and job section (direct/indirect) were included.

\section{Data analysis}

The responses of participants were analyzed with structural equation modeling (SEM) techniques, using the AMOS 7 software package ${ }^{35)}$. We analyzed the covariance matrix using the maximum likelihood method of estimation. Besides the $\chi^{2}$ statistic, the analysis assessed the goodness-of-fit index (GFI), the root mean square error of approximation (RMSEA), the non-normed fit index (NNFI), and the comparative fit index (CFI) were used. The theoretical model we tested is presented in Fig. 1 (Please note that Fig. 1 also presents the results of SEM). Because of the large number of items, it was not possible to conduct SEM-analysis on a full disaggregation model. Therefore, the scales introduced above were used as indicators of the latent factors. All latent factors had two or three indicators except for job performance which had only one indicator. To control for random measurement error for this factor, the error variance of job performance was set equal to zero.

\section{Results}

\section{Descriptive statistics}

The means, standard deviations, internal consistencies (Cronbach's alpha), and correlations between the study variables are displayed in Table 1. As can be seen, all variables have satisfactory reliabilities with Cronbach's alpha coefficients of 0.70 or higher, which were comparable with previous studies ${ }^{9,30)}$.

\section{Model testing}

Results of the SEM-analyses showed that the proposed model (displayed in Fig. 1) fits adequately to the data; $\chi^{2}(29)=159.27, \quad$ GFI $=0.96, \quad \mathrm{NNFI}=0.94, \quad \mathrm{CFI}=0.96$, RMSEA $=0.08$. As expected (Hypothesis 1), workaholism and work engagement were weakly and positively relat- 


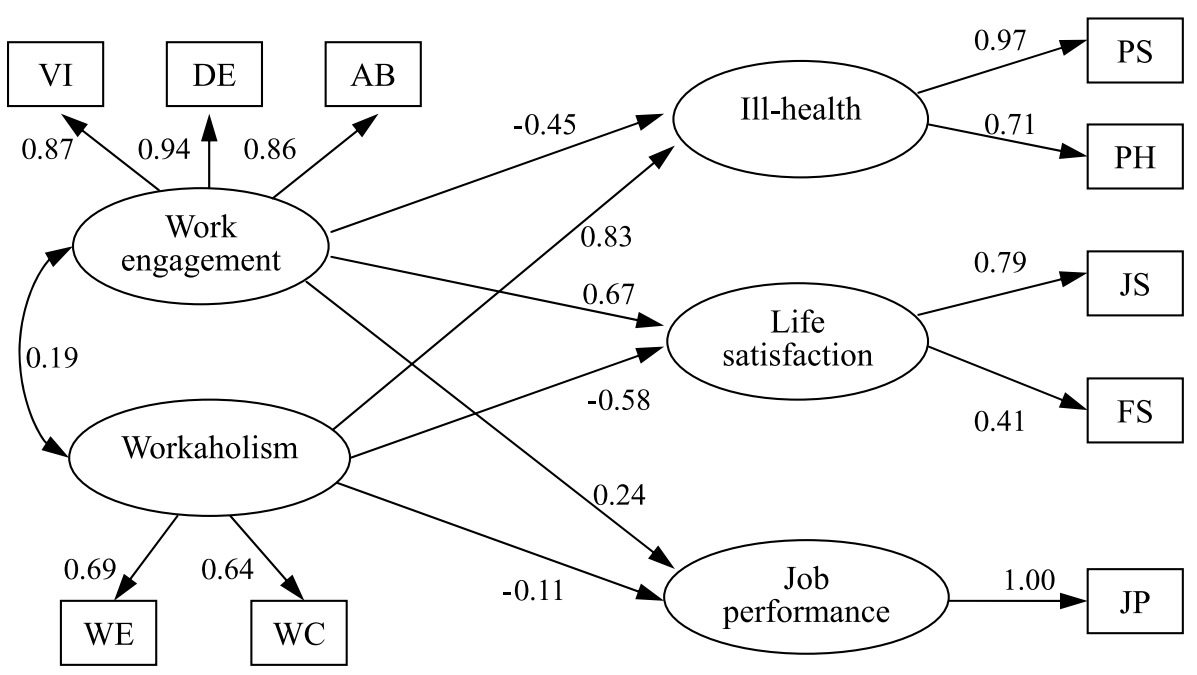

Fig. 1. Standardized solution (Maximum Likelihood estimates) of the hypothesized model. $\mathbf{N}=\mathbf{7 7 6}$. $\mathrm{VI}=$ Vigor; $\mathrm{DE}=$ Dedication; $\mathrm{AB}=$ Absorption; WE=Working Excessively; WC=Working Compulsively; PS=Psychological Distress; PH=Physical Complaints; JS=Job Satisfaction; FS=Family Satisfaction; $\mathrm{JP}=$ Job Performance.

Table 1. Means, SDs, Internal consistency (Cronbach's alpha on the diagonal), and Correlations of the variables used in the study ( $\mathrm{n}=\mathbf{7 7 6}^{\mathrm{a}}$ )

\begin{tabular}{|c|c|c|c|c|c|c|c|c|c|c|c|c|c|c|c|c|}
\hline Measures & \# items & Mean & SD & 1 & 2 & 3 & 4 & 5 & 6 & 7 & 8 & 9 & 10 & 11 & 12 & 13 \\
\hline 1 Age & - & 38.1 & 12.8 & - & -0.02 & $-0.17^{* * * *}$ & -0.11 ** & $-0.13 * * *$ & $0.30 * * *$ & $0.28 * * *$ & $0.26 * * *$ & $-0.28 * * *$ & $-0.16^{* * * *}$ & $0.26 * * *$ & $0.11 * *$ & $0.22 * * *$ \\
\hline 2 Gender $^{b}$ & - & 1.1 & 0.2 & & - & -0.30 *** & -0.05 & $-0.08^{*}$ & -0.05 & -0.03 & -0.02 & -0.01 & $0.08 *$ & -0.03 & $0.07^{\dagger}$ & -0.05 \\
\hline 3 Section $^{\mathrm{c}}$ & - & 1.7 & 0.4 & & & - & $0.07^{\dagger}$ & $0.20 * * *$ & -0.02 & $-0.07^{\dagger}$ & $-0.09 *$ & $0.16^{* * *}$ & $0.15^{* * *}$ & $-0.10 * *$ & -0.06 & $0.11^{* *}$ \\
\hline 4 Work excessively & 5 & 10.4 & 3.2 & & & & 0.70 & $0.49 * * *$ & -0.04 & 0.04 & $0.08 *$ & $0.52^{* * * *}$ & $0.38^{* * *}$ & $-0.28 * * *$ & $-0.12^{* * * *}$ & 0.01 \\
\hline 5 Work compulsively & 5 & 9.8 & 3.1 & & & & & 0.70 & $0.21 * * *$ & $0.19 * * *$ & $0.24 * * *$ & $0.39 * * *$ & $0.31 * * *$ & $-0.12 * *$ & $-0.11 * *$ & $-0.08^{*}$ \\
\hline 6 Vigor & 3 & 10.8 & 4.3 & & & & & & 0.84 & $0.82 * * *$ & $0.75^{* * *}$ & $-0.29 * * *$ & $-0.23 * * *$ & $0.41 * * *$ & $0.17 * * *$ & $0.17 * * *$ \\
\hline 7 Dedication & 3 & 11.5 & 4.0 & & & & & & & 0.78 & $0.81 * * *$ & $-0.27 * * *$ & $-0.17 * * *$ & $0.42 * * *$ & $0.20^{* * *}$ & $0.24 * * *$ \\
\hline 8 Absorption & 3 & 10.1 & 4.1 & & & & & & & & 0.81 & $-0.18^{* * * *}$ & $-0.09 *$ & $0.38 * * *$ & $0.13^{* * *}$ & $0.15^{* * *}$ \\
\hline 9 Psychological distress & 15 & 30.2 & 9.6 & & & & & & & & & 0.93 & $0.68^{* * *}$ & $-0.50^{* * * *}$ & $-0.31^{* * * *}$ & $-0.16^{* * * *}$ \\
\hline 10 Physical complaints & 11 & 19.6 & 6.5 & & & & & & & & & & 0.88 & $-0.36 * * *$ & $-0.21 * * *$ & $-0.09 *$ \\
\hline 11 Job satisfaction & 1 & 2.6 & 0.8 & & & & & & & & & & & - & $0.33^{* * * *}$ & $0.14 * * *$ \\
\hline 12 Family satisfaction & 1 & 3.0 & 0.8 & & & & & & & & & & & & - & $0.12 * * *$ \\
\hline 13 Job performance & 1 & 6.6 & 2.0 & & & & & & & & & & & & & - \\
\hline
\end{tabular}

ed to each other $(r=0.19, p<0.001)$. Furthermore, workaholism was positively related to ill-health $(\beta=0.83$, $p<0.001)$ and negatively related to life satisfaction and job performance $(\beta=-0.58, p<0.001 ; \beta=-0.11, p<0.01)$. On the other hand, work engagement was negatively related to ill-health $(\beta=-0.45, p<0.001)$ and positively related to life satisfaction and job performance $(\beta=0.67, p<0.001$; $\beta=0.24, p<0.01)$. These results suggest that Hypothesis 2 and 3 are confirmed as well.

In a next step, we conducted additional analysis to control for potential confounders (i.e., age, gender, and job section). Specifically, each control variable was included in the proposed model as a manifest variable simultaneously and was allowed to have effects on all variables in the model. After controlling for confounding variables, the path coefficients were virtually the same as those of the proposed model, but the model fit decreased $\left(\chi^{2}(32)=278.35, \quad \mathrm{GFI}=0.95, \quad \mathrm{NNFI}=0.84, \quad \mathrm{CFI}=0.93\right.$, RMSEA=0.10). These results indicate that the relationships of the control variables to the model variables were weak and inconsistent. Importantly, the control variables did not affect the structural paths in the model. Therefore, the control variables were removed from final model in Fig. 1.

\section{Discussion}

This study examined the distinctiveness of workaholism and work engagement in terms of their relationships with well-being among Japanese employees. Results of SEM 
showed that although workaholism and work engagement are weakly and positively related to each other, their associations with well-being are different; workaholism is related to unwell-being, whereas work engagement to well-being. This means workaholism and work engagement can be empirically differentiated from each other.

As expected in Hypothesis 1, workaholism and work engagement are weakly and positively related to each other $(r=0.19)$, sharing only $3.6 \%$ of their variances. This suggests that workaholism and work engagement seem two different kinds of concepts, presumably because the motivation underlying hard working differs fundamentally; workaholics are propelled by an obsessive inner drive they cannot resist whereas engaged employees are intrinsically motivated ${ }^{8}$. Future researches need to clarify their underlying motivation empirically.

Hypothesis 2, which stated that workaholism is positively related to ill-health and negatively related to life satisfaction and job performance, was confirmed as well. It is important to note that workaholism had stronger relationship with ill-health $(\beta=0.83)$ compared to life satisfaction and job performance $(\beta=-0.58$ and -0.11 , respectively). The relative strong association with ill-health underlines the importance of health component for workaholism. Previous research revealed that workaholism is related to a wide range of outcomes including ill-health (psychological distress, physical complaints), life satisfaction, and job performance $3,4,9,11-14,18,20,22)$. The current study suggests that workaholism has a larger impact on health than on the other indicators of well-being. Since workaholism have been considered as a "desirable" characteristic, its adverse health effects should be more emphasized. Differentiating between "good" workaholism (i.e., work engagement) and real or "bad" workaholism is a possible first step.

It is also notable that workaholism was negatively related to job performance. This means that if employees work excessively hard in a compulsive fashion, their performance is not automatically superior to those who work less frantic; sometimes it's even worse. To date, virtually no empirical research has been carried out on the relationship between workaholism and job performance except for Schaufeli et al. (2006) ${ }^{23)}$. Although Schaufeli et al. (2006) ${ }^{23)}$ showed that both components of workaholism (i.e., work excessively hard and working compulsively) were weakly positively related to self-reported extra-role performance (but unrelated to in-role performance), our results seem plausible because extra-role performance suggests a hallmark of workaholism (i.e., working beyond what is reasonably required by the job or by the organization). Hence, seemingly inconsistent results may be explained by different measures of job performance (i.e., overall performance vs. extra-role perfor- mance). In addition, the long list of negative attitudes and behaviors of workaholics that might interfere with job performance $^{5)}$ can make our results plausible as well. More specifically, since workaholics spend more time on their work, they may become emotionally or cognitively exhausted over time ${ }^{11}$, which can lead to poor performance. Furthermore, since workaholics are so deeply involved in their work, they have unreasonably high performance standards ${ }^{36}$, which can lead to more negative perceptions of one's own abilities and performance ${ }^{3)}$.

Hypothesis 3, which stated that work engagement is negatively related to ill-health and positively related to life satisfaction and job performance, was also confirmed. The relatively strong association of work engagement with life satisfaction (especially with job satisfaction, $\beta=0.67)$ underlines the motivational role of work engagement ${ }^{8,29)}$. In addition, work engagement plays a health enhancing role; it was negatively related to ill-health (i.e., psychological distress and physical complaints). According to Hallberg and Schaufeli (2006) ${ }^{37)}$, this health component is an important conceptual aspect that separates work engagement from other proactive organizational attitudes like organizational commitment, which refers to the emotional attachment that employees form with their organization, based on shared values and interests $^{38)}$. Therefore, from the viewpoint of health, work engagement plays a health enhancing role whereas workaholism plays a health impairment role.

\section{Limitations}

This study had some limitations. First, this study was based on a cross-sectional design, so no conclusion can be drawn about any causal order. In addition, long-term effects of workaholism and work engagement are unknown. Second, this study is based on survey data with self-report measures. Next to self-report bias due to e.g. negative affect, common method variance might have played a role, although several studies showed that these influences are not as high as could be expected ${ }^{39,40)}$. Nevertheless, our findings should be repeated with objective indicators (e.g., blood pressure, objective performance) in the future. Third, participants were Japanese employees in a construction machinery company. Generalization of the current results to other occupations and even in other countries awaits further empirical examination.

\section{Practical implications}

Our findings suggest that workaholism is associated with unwell-being, whereas work engagement is associated with well-being. So, decreasing workaholism and improving work engagement are both possible ways to improve employees' well-being. 
In terms of decrease in workaholism, the organizational culture in which employees who work long hours are the "heroes" who are displayed as role models should be replaced by a culture that stimulates working smart rather than hard and that values a healthy work-life balance. This is not an easy thing to accomplish, though, because those who are in charge of that culture change are often work addicts themselves.

For employees who are at risk for workaholism, training programs which focus on time management and problem solving skills might be helpful, because workaholics take more work than they can handle and accept new tasks before completing previous ones ${ }^{41)}$. Programs which focus on assertiveness might be also helpful in order to deal adequately with the social demands in their work environment by using such strategies as saying "no" to clients, colleagues or superiors, or to holding one's own priorities $^{42)}$. In addition, to prevent workaholism, employees should be encouraged to detach and recover from a hard day's work. A demanding work situation increases the need for recovery because it draws on an individual's resources ${ }^{43}$. Successive depletion of resources will result in negative effects, such as fatigue and, eventually, when no recovery occurs, in exhaustion. Distraction may help employees detach and recover from their work ${ }^{44)}$.

It has been found that job resources (e.g., autonomy, performance feedback, social support, supervisory coaching) and personal resources (e.g., self-efficacy, resilience, self-esteem, optimistic) are antecedents of work engagement $^{26,29)}$. So, increasing job resources may have a positive impact on work engagement. This can be achieved, for instance, by participative management, by increasing social support, by providing positive feedback from supervisors, and by team building. In addition, empowering personal resources is another way to boost work engagement, for instance, by training programs that focus on increasing optimism, resilience or self-efficacy ${ }^{45}$.

\section{Conclusion}

Workaholism and work engagement are weakly and positively related with each other, but they are two different kinds of concepts; workaholism is associated with unwell-being, whereas work engagement with well-being. Therefore, we can conclude that workaholism has adverse effects on employees' well-being, whereas work engagement has favorable effects on it. The take-home message of our study is that workaholism is bad for employee's well-being, whereas work engagement is beneficial.

\section{References}

1) Sullivan SE (1999) The changing nature of careers: a review and research agenda. J Manage 25, 457-84.

2) Jones F, Burke RJ, Westman M (2006) Work-life balance: key issues. In: Work-life balance: a psychological perspective, Jones F, Burke RJ, Westman M (Eds.), 1-9, Psychology Press, East Sussex.

3) $\mathrm{Ng} \mathrm{TWH}$, Sorensen KL, Feldman DC (2007) Dimensions, antecedents, and consequences of workaholism: a conceptual integration and extension. J Organ Behav 28, 111-36.

4) Schaufeli WB, Taris TW, Van Rhenen W (2008) Workaholism, burnout and engagement: three of a kind or three different kinds of employee well-being. Appl Psychol Int Rev 57, 173-203.

5) Scott KS, Moore KS, Miceli MP (1997) An exploration of the meaning and consequences of workaholism. Hum Relat 50, 287-314.

6) Maslach C, Schaufeli WB, Leiter MP (2001) Job burnout. Annu Rev Psychol 52, 397-422.

7) Schaufeli WB, Salanova M, González-Romá V, Bakker $\mathrm{AB}$ (2002) The measurement of engagement and burnout: a confirmatory factor analytic approach. J Happiness Stud 3, 71-92.

8) Schaufeli WB, Taris TW, Le Blanc P, Peeters MCW, Bakker AB, De Jonge J (2001) Maakt arbeid gezond? Op zoek naar de bevlogen werknemer [May work produce health? The quest for the engaged worker]. De Psycholoog 36, 422-8 (in Dutch).

9) Sonnentag S (2003) Recovery, work engagement, and proactive behavior: a new look at the interface between nonwork and work. J Appl Psychol 88, 518-28.

10) Schaufeli WB, Shimazu A, Taris TW (2009) Being driven to work excessively hard: the evaluation of a twofactor measure of workaholism in the Netherlands and Japan. Cross Cult Res (in press).

11) Taris TW, Schaufeli WB, Verhoeven LC (2005) Internal and external validation of the Dutch Work Addiction Risk Test: implications for jobs and non-work conflict. Appl Psychol Int Rev 54, 37-60.

12) Burke RJ (1999) It's not how hard you work but how you work hard: evaluating workaholism components. Int J Stress Manage 6, 225-40.

13) Burke RJ (2000) Workaholism components, job satisfaction, and career progress. J Appl Soc Psychol 31, 2339-56.

14) Burke RJ, Richardsen AM, Mortinussen M (2004) Workaholism among Norwegian managers: work and well-being outcomes. J Organ Change Manag 7, 459-70.

15) Kanai A, Wakabayashi M, Fling S (1996) Workaholism among employees in Japanese corporations: an examination based on the Japanese version of the Workaholism Scales. Jpn Psychol Res 38, 192-203.

16) McMillan LHW, O’Driscoll MP, Burke RJ (2003) Workaholism: a review of theory, research, and future 
directions. In: International review of industrial and organizational psychology, Cooper CL and Robertson IT (Eds.), vol. 18, 167-89, Wiley, New York.

17) Spence JT, Robbins AS (1992) Workaholism: definition, measurement, and preliminary results. J Pers Assess 58, 160-78.

18) Burke RJ (1999) Are workaholics job satisfied and successful in their careers? Career Dev Int 4, 277-82.

19) Taris TW, Schaufeli WB, Shimazu A (in press) The push and pull of work: about the differences between workaholism and work engagement. In: Work engagement: a handbook of essential theory and research, Bakker AB and Leiter MP (Eds.), Psychology Press, London.

20) Burke RJ (1999) Workaholism and extra-work satisfaction. Int J Organ Anal 7, 352-64.

21) Bakker AB, Demerouti E, Burke RJ (2009) Workaholism and relationship quality: a spillovercrossover perspective. J Occup Health Psych 14, 23-33.

22) Robinson BE, Flowers C, Carroll J (2001) Work stress and marriage: a theoretical model examining the relationships between workaholism and marital cohesion. Int J Stress Manage 8, 165-175.

23) Schaufeli WB, Taris TW, Bakker AB (2006) Dr Jekyll or Mr Hyde? On the differences between work engagement and workaholism. In: Research companion to working time and work addiction, Burke RJ (Ed.), 193-217, Edward Elgar, Cheltenham.

24) Demerouti E, Bakker AB, Janssen PPM, Schaufeli WB (2001) Burnout and engagement at work as a function of demands and control. Scand J Work Environ Health 27, 279-86.

25) Shimazu A, Schaufeli WB, Kosugi S, Suzuki A, Nashiwa H, Kato A, Sakamoto M, Irimajiri H, Amano S, Hirohata K, Goto R, Kitaoka-Higashiguchi K (2008) Work Engagement in Japan: validation of the Japanese version of the Utrecht Work Engagement Scale. Appl Psychol Int Rev 57, 510-23.

26) Bakker $A B$ (2008) Building engagement in the workplace. In: The peak performing organization, Cooper CL and Burke RJ (Eds.), 50-72, Routledge, Oxon.

27) Salanova M, Agut S, Peiro JM (2005) Linking organizational resources and work engagement to employee performance and customer loyalty: the mediation of service climate. J Appl Psychol 90, 1217-27.

28) Xanthopoulou D, Bakker AB, Demerouti E, Schaufeli WB (2009) Work engagement and financial returns: a diary study on the role of job and personal resources. $\mathrm{J}$ Occup Organ Psych 82, 183-200.

29) Schaufeli WB, Bakker AB (2004) Job demands, job resources, and their relationship with burnout and engagement: a multi-sample study. J Organ Behav 25, 293-315.

30) Shimomitsu T, Yokoyama K, Ono Y, Maruta T, Tanigawa T (1998) Development of a novel brief job stress questionnaire. In: Report of the research grant for the prevention of work-related diseases from the Ministry of Labour, Kato S (Ed.) 107-15, Ministry of Labour, Tokyo (in Japanese).

31) De Jonge J, Dollard MF, Dormann C, Le Blanc PM, Houtman ILD (2000) The demand-control model: specific demands, specific control, and well-defined groups. Int J Stress Manage 7, 269-87.

32) Scarpello V, Campbell JP (1983) Job satisfaction: are all the parts there? Personnel Psychol 36, 577-600.

33) Wanous JP, Reichers AE, Hudy MJ (1997) Overall job satisfaction: how good are single item measures? J Appl Psychol 82, 247-52.

34) Kessler RC, Barber C, Beck A, Berglund P, Cleary PD, McKenas D, Pronk N, Simon G, Stang P, Ustun TB, Wang P (2003) The world health organization health and work performance questionnaire (HPQ). J Occup Environ Med 45, 156-74.

35) Arbuckle JL (2006) Amos (Version 7.0) [Computer Program], SPSS, Chicago.

36) Porter G (1996) Organizational impact of workaholism: suggestions for researching the negative outcomes of excessive work. J Occup Health Psychol 1, 70-84.

37) Hallberg UE, Schaufeli WB (2006) "Same same" but different? Can work engagement be discriminated from job involvement and organizational commitment? Eur Psychologist 11, 119-27.

38) Meyer JP, Allen NJ (1997) Commitment in the workplace: theory, research, and application, Sage, London.

39) Edwards JR (2008) To prosper, organizational psychology should ... overcome methodological barriers to progress. J Organ Behav 29, 469-91.

40) Spector PE (2006) Method variance in organizational research: truth or urban legend? Organ Res Methods 9, 221-32.

41) Van Wijhe C, Schaufeli WB, Peeters MCW (in press) Understanding and treating workaholism: setting the stage for successful interventions. In: Psychological and behavioural risks at work, Cooper CL and Burke RJ (Eds.), Wiley, Chichester.

42) Schabracq MJ (2005) Well-being and Health. What HRM can do about it. In: Reinventing HRM, Burke RJ and Cooper CL (Eds.), 187-206, Routledge, London \& New York.

43) Zijlstra FRH (1996) Effort as energy regulation. In: Processes of the molar regulation of behavior, Battmann W and Dutke S (Eds.), 219-35, Pabst Science Publishers, Berlin.

44) Shimazu A, Schaufeli WB (2007) Does distraction facilitate problem-focused coping with job stress? A one year longitudinal study. J Behav Med 30, 423-34.

45) Luthans F, Avey JB, Patera JL (2008) Experimental analysis of a web-based training intervention to develop positive psychological capital. Acad Manage Learn Educ 7, 209-21. 